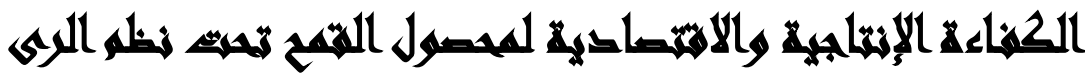

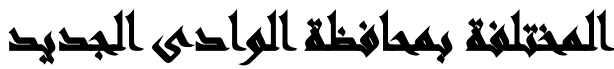

\section{$[1 Y]$}

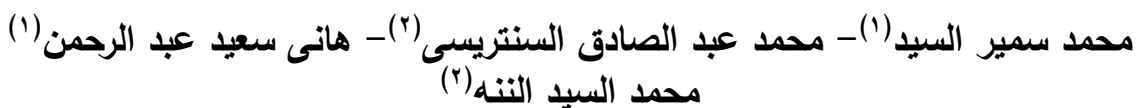

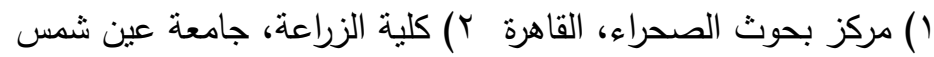

\section{المستخلص}

يعتبر محصول القمح من أهم المحاصيل الغذائية التى تعتمد عليها الكائنات الحية كعنصر أساسى للغذاء، كذللك تقوم على تجهيزاته خدمات وصناعات الفيات عديدة تنيح مجالات متعددة للإستثمار والتشغيل، فمنها ما يستخدم في صناعاعة الإعاء الخبز ويساهم كغذاء مباثر

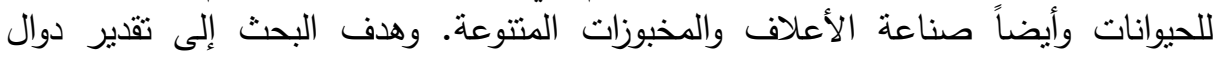
الإنتاج والتكاليف لمحصول القمح. تقدير بعض مقاييس الكفاءة الإنتاجية والاقتصادية للمحصول وتقدير الحجم الذى يعظم الربح وكذللك الحجم الأمتل الذي يدائي الإني التكاليف

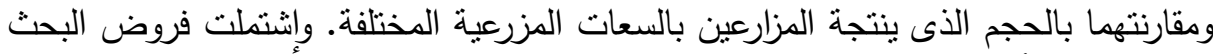

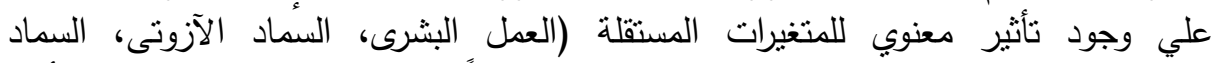

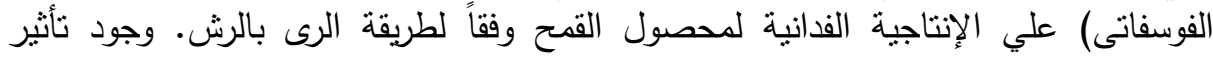

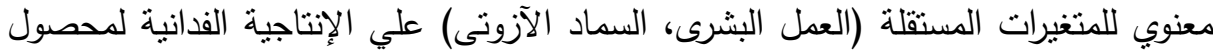

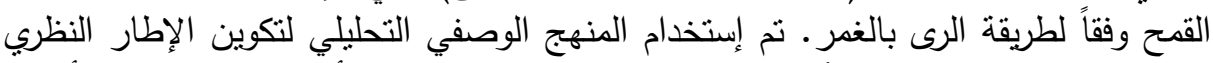

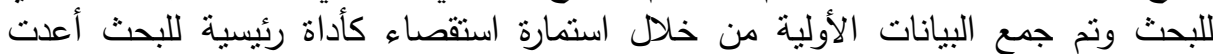

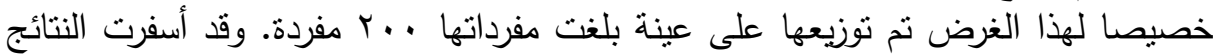

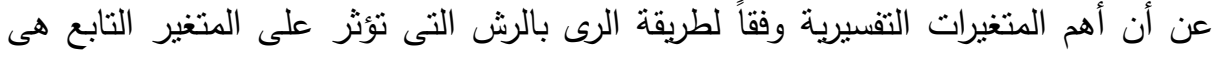

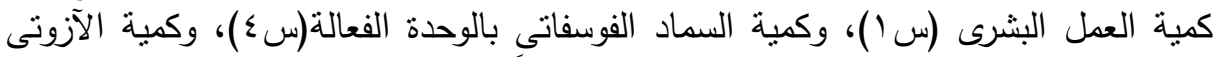

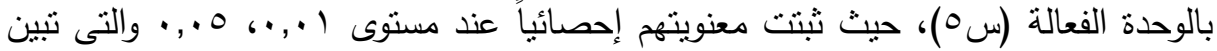
منها العلاقة الطردية وذللك لإتفاق إثنارتهم مع المنطق الإقتصادى.

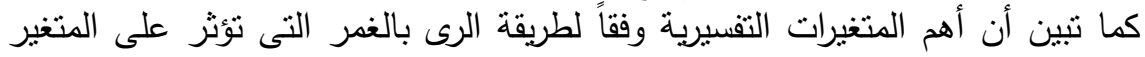

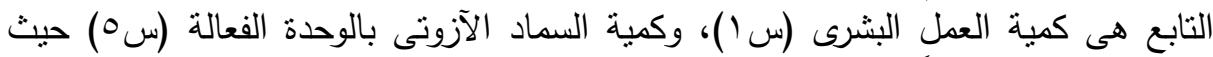

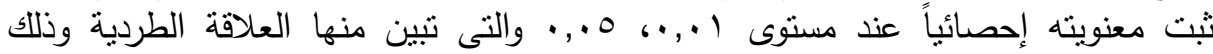

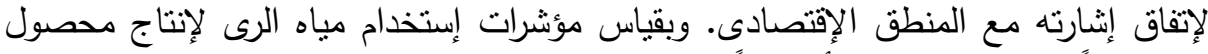

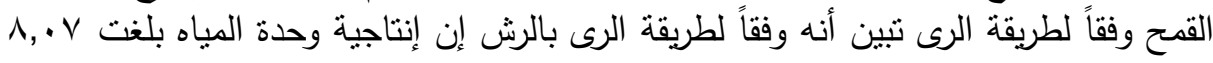




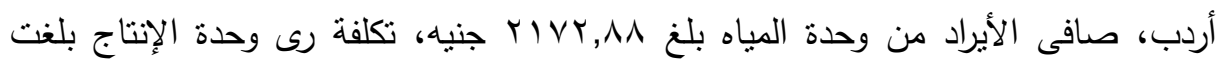

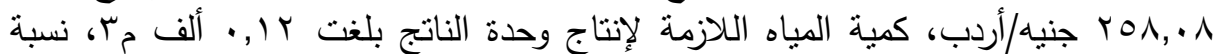

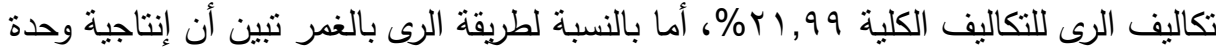

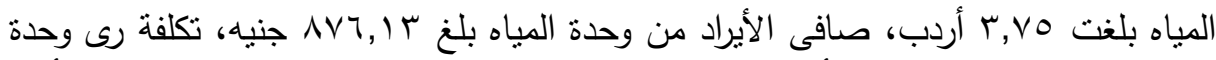

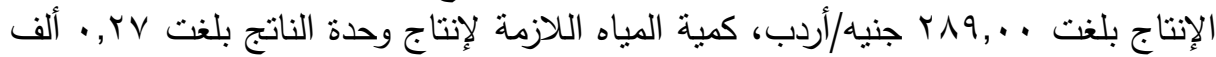

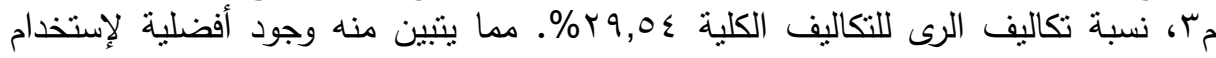
طريقة الرى بالرش مقارنة بإستخدام طريقة الرى بالغمر . لإن

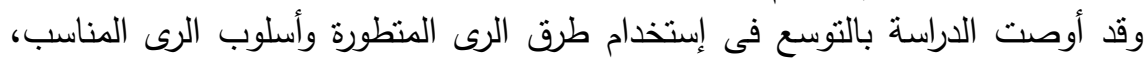

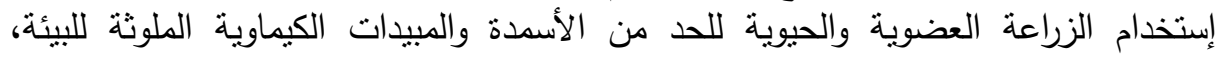

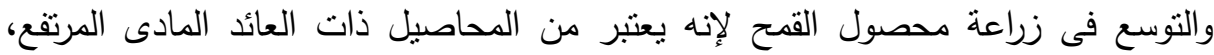

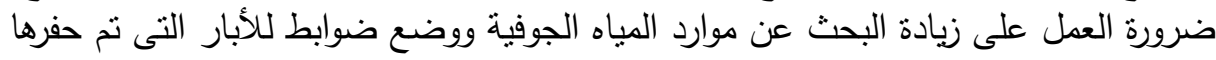
والعمل على كفاءة إستخدامها.

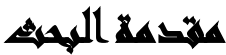

تمنل الزراعة أحد الركائز الأساسية فى تحقيق أهداف التتمية الإقتصادية والإجتماعية بإعنبارها أحد القواعد الأساسية للنمو الإقتصادى، إذ يقع عليها العبء الأكبر فى توفير المواد الأدئ

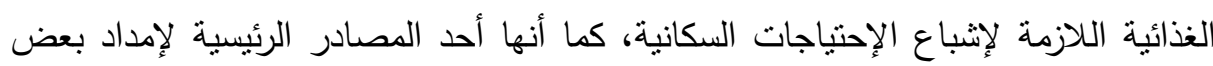

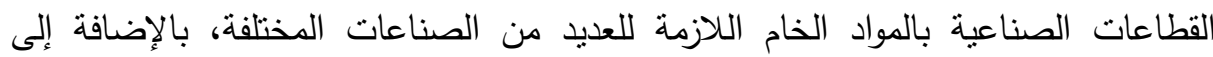
إستيعاب الكثير من الأبدي العاملة، وإعتبارها أحد المصادر الأساسية للصادرات، وكونها المصدر الأساسي لاخل نسبة كبيرة من المشتغلين بها وعلي الرغم من الجهود المبذولة تجاه

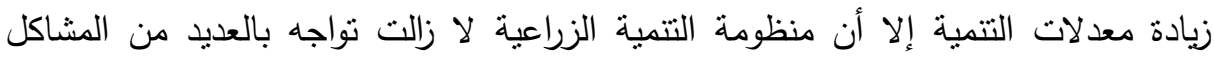

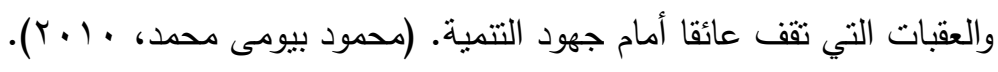

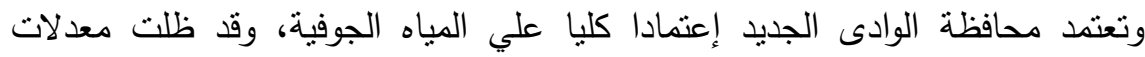

التتمية الزراعية والصناعية تعتمد علي جهود الدولة فقط في مجال حفر الآبار، إلا أنه ومنذ

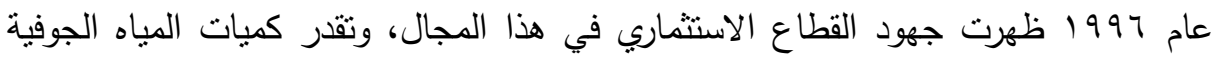
المتاحة والتي يمكن استخدامها في التوسع المستقبلي للأراضي الزراعية بمحافظة الوادي

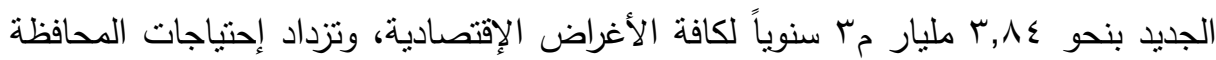
من المياه الجوفية نتيجة زيادة عدد السكان من حوالي ^, اء ألف ألف نسمه عام 1997 1، إلي الي

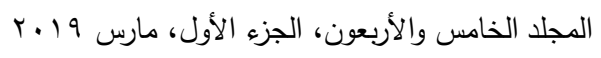




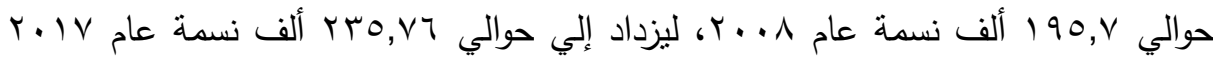

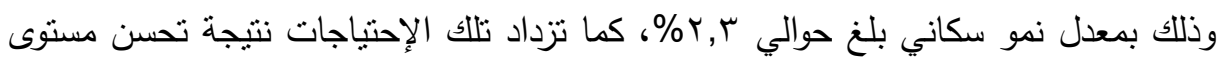

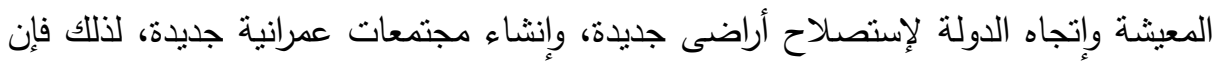
من أكبر التحديات التي تواجه المحافظة هي الحفاظ علي المخزون الجوفى لتحقيق التتمية التهاه المستدامة، وتحقيق النوازن بين موارد المياه الجوفية، والطلب المتزايد عليها (محافظة الوادى لونى

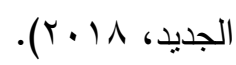

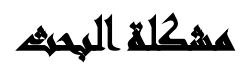

تعتبر الموارد المائية أحد أهم مقومات الإنتاج الزراعى فى مصر، وعلى الرغم من أن

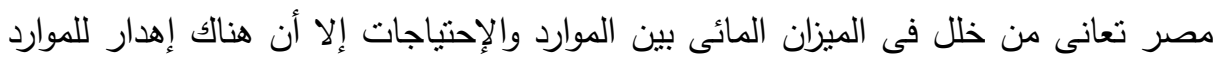

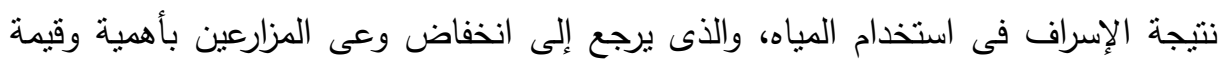

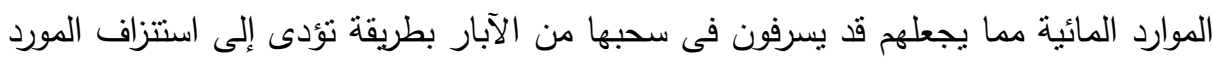

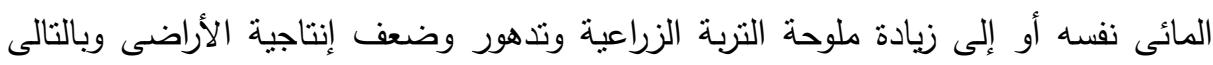

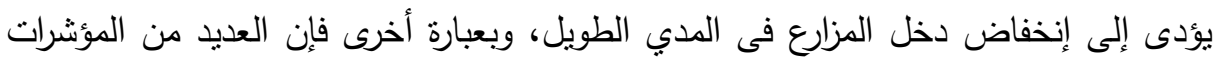

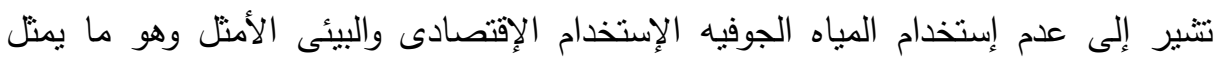

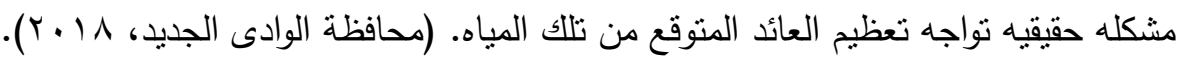

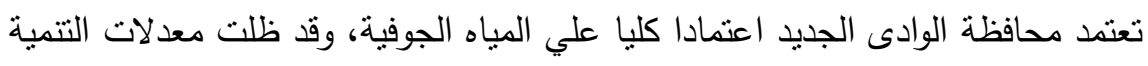
الزراعية والصناعية تعتمد علي جهود الدولة فقط في مجال حفر الآبار، إلا أنه ومنذ عام 999 ظهرت جهود القطاع الإستثماري في هذا المجال، وتقدر كميات المياه الجوفية المناحة والتي يمكن استخدامها في التوسع المستقبلي للأراضي الزراعية بمحافظة الوادي الجديد بنحو

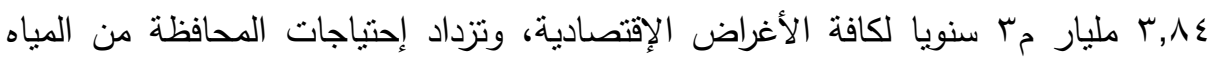

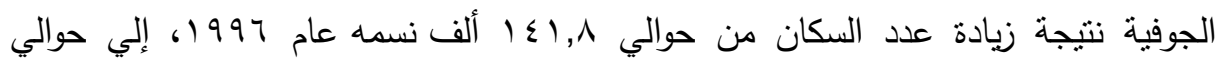

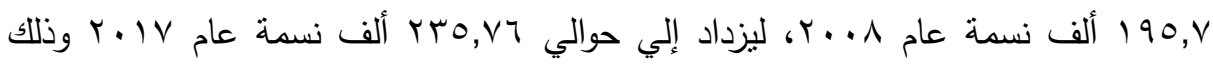

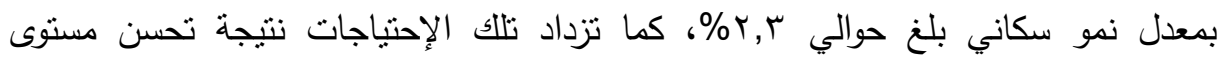
المعيشة واتجاه الدولة لإستصلاح أراضى جديدة، وإنشاء مجتمعات عمرانية جديدة بالمحافظة، تُودئ

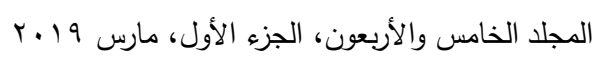


لذلك فإن من أكبر التحديات التي تواجه المحافظة هي الحفاظ علي المخزون الجوفى لتحقيق

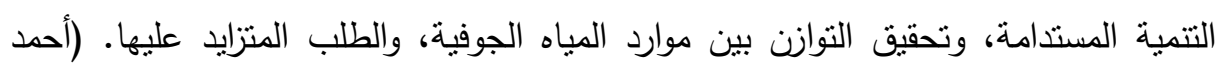

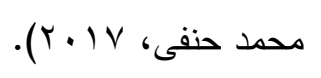

\section{أسئل المهيم}

1- ما مدى تأثنر إستخدام طريقة الرى بالرش أو الرى بالغمر لاي مزارعي القمح علي الكفاءة

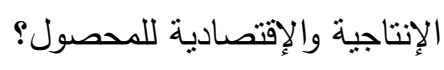

r- إلى أى مدى يساهم ذللك في تقدير الحجم الذى يعظم الربح والحجم الأمنل الذي يدني

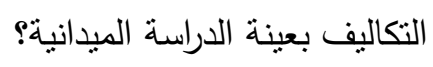

\section{أهما اهت المهمث}

$$
\text { يهدف البحث إلى تحقيق الأهداف التالية: }
$$

r- تقدير بعض مقاييس الكفاءة الإنتاجية والاقتصادية للمحصول وتقدير الحجم الذى يعظم الربح وكذلك الحجم الأمتل الذي يدني التكاليف ومقارنتهما بالحجم الذى ينتجه المزارعين

$$
\text { وفقاً لطريقة الرى المستخدمة. }
$$

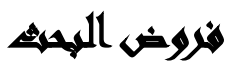

1- يوجد نأثير معنوي ذات دلالة للمتغيرات المستقلة (العمل البشرى، السماد الفوسفاتى، السماد الآزوتى) علي الإنتاجية الفدانية لمحصول القمح وفقاً لطريقة الرى بالرش.

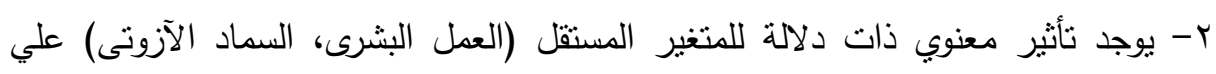

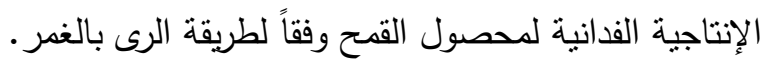




\section{متغيجايت المهيه}

يبني البحث الحالي نموذجا إفتراضيا للدالة الإنتاجية يعبر عن العلاقة التأثبرية المنطقية والإحصائية بين المتغيرات المستقلة والمتغير التابع حيث أن البحث يحتوي على أكثر من

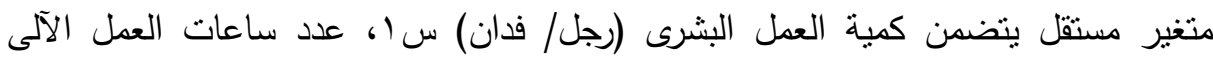
(ساعة/ فدان) س ب، كمية التقاوى (كجم/ فدان) سمب، كمية السماد الفوسفاتى بالوحدة الفعالة سء، كمية السماد الآزوتى بالوحدة الفعالة سه، ومتغير واحد تابع هو إنتاج الفدان بالطن بلهن

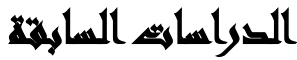

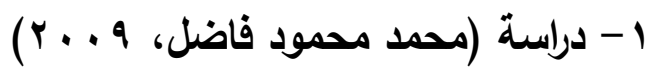
• • دراسة عوامل التتمية الزراعية بمحافظة الوادى الجديد. • دراسة الإنتاجية وتطور المساحات المزروعة لمحصول القمح بمحافظة الوادى الجديد.

• تطور المساحات المزروعة لمحصول القمح بمحافظة الوادى الجديد حيث وصلت المساحة

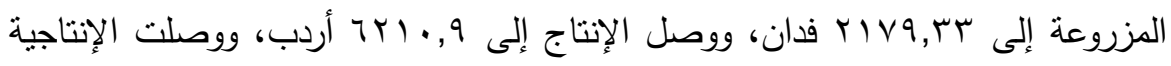

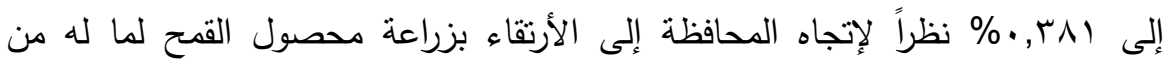
• أوضحت الدراسة إلى أنه للوصول لتدنى التكاليف الإنتاجية فإن الحجم الأمتل المطلوب

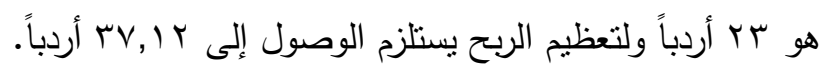

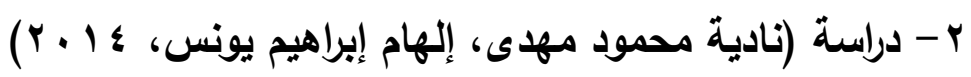

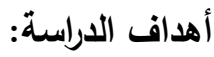
• تقييم الجدارة الإنتاجية للأراضى الزراعية بمحافظات الصحارى وذللك وفقاً للجدارة الإنتاجية

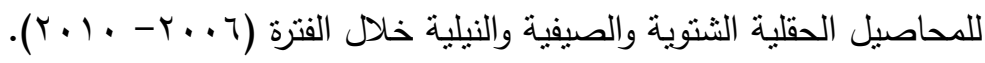


• قياس الكفاءة الفنية للجدارة الإنتاجية لمراكز وقرى محافظات الصحارى. النتائج: بتصنيف الرقعة الإرضية المزروعة وفقاً للغلة الفدانية للمحاصيل الحقلية منفردة، تبين أن بعض مراكز محافظات الصحارى جاءت فى الرتبة الإنتاجية الأولى (عالية الإنتاجية)

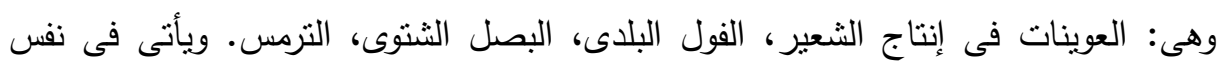

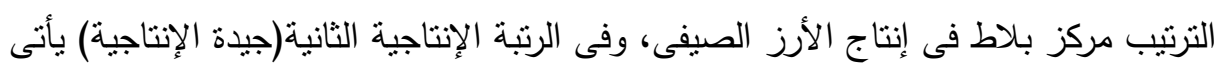

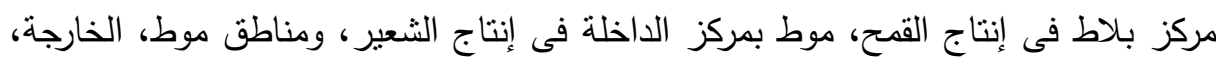

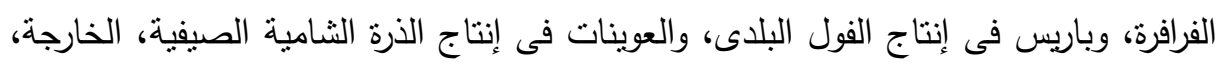

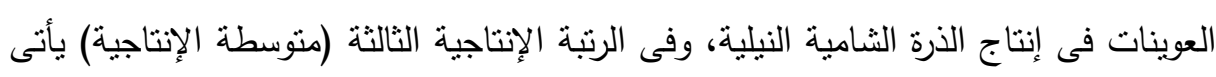

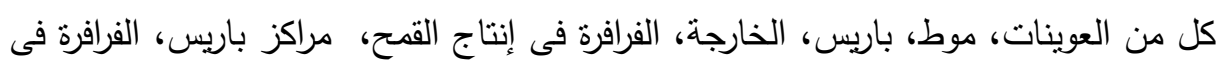
إنتاج الثعير ، مركز بلاط فى إنتاج الفول البلدى، وقرية موط فى إنتاج العدس.

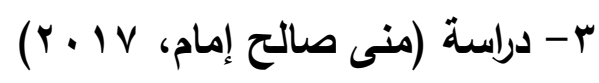
أهداف الدراسة:

• التعرف على إنتاج محصول القحح فى مصر بصفة عامة ومحافظة الوادى الجديد بصفة خاصة. التعرف على إقتصاديات إنتاج محصول القمح بمحافظة الوادى الجديد من خلال تقدير دوال الإنتاج والتكاليف.

النتائج:

تنين من الدراسة أن أكثر العوامل تأثنراً على الكمية المنتجة من القمح على مستوى العينة

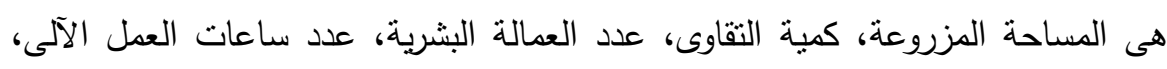
كمية السماد البلدى، كمية السماد السوبر فوسفات. •بتقدير دالة التكاليف الكلية على مسنوى العينة أشنارت النتائج أن مرونة التكاليف بلغت نحو 1 , إوهذا يشير إلى أن منتجى العينة يعملون فى مرحلة الإنتاج الإقتصادي.

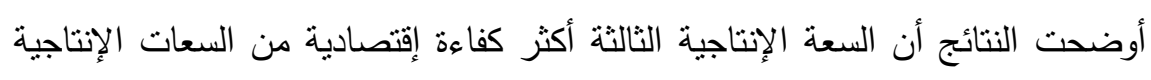

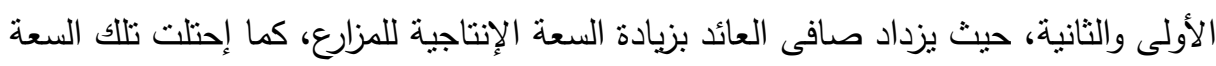


المرتبة الأولى بالنسبة لمعدل العائد على الجنيه المستثمر وقد بلغ نحو V9, •، وكان متوسط

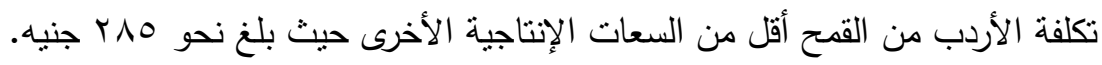

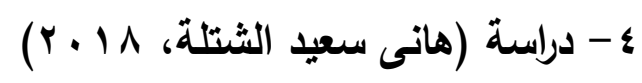
أهداف الدراسة:

• التعرف على حجم الموارد المائية المتاحة بمحافظة بالوادى الجديد وتتميتها.

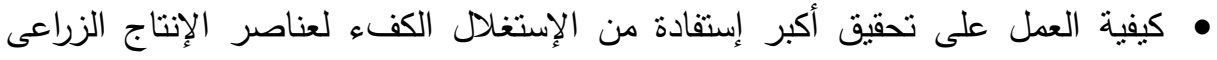
المتاحة. • تعظيم إنتاجية الوحدة من هذه الموارد المستغلة لتحقيق أهداف التتمية الزراعية بمحافظة الوادى الجديد.

النتائج: • أوضحت الدراسة نوزيع الآبار الحكومية والإستتمارية والأهالى وحجم الإستهلاك السنوى

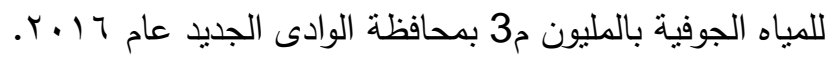

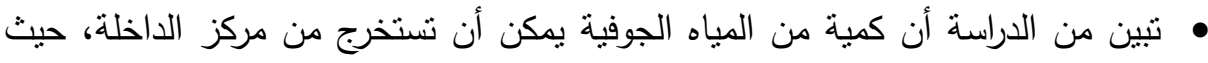
بلغت كمية المياه المستهلكة به وبمنطقة شرق العوينات لكل من الآبار الحكومية،

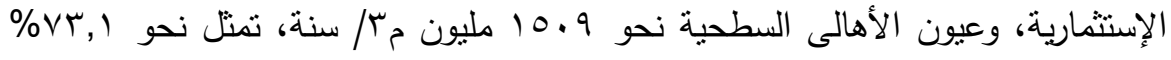

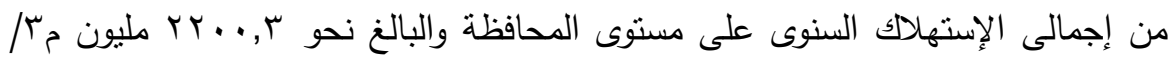

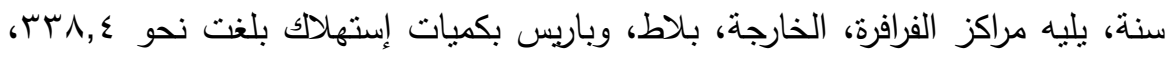
\&

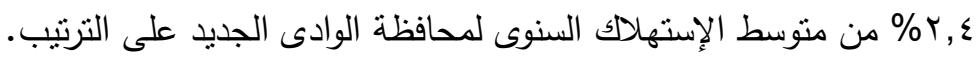

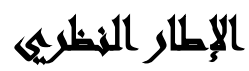

المفاهيم الاقتصادية المستخدمة فى الدراسة مفهوم الكفاءة الإنتاجية: العلاقة بين كمية الموارد المستخدمة فى العملية الإنتاجية وبين

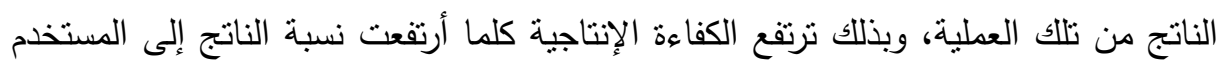

$$
\text { المجلد الخامس والأربعون، الجزء الأول، مارس } 19
$$


من الموارد وهى الأداء السليم للعناصر المنتجة فى أى منشأة، وهو الذى يتم فى الوقت الملائم

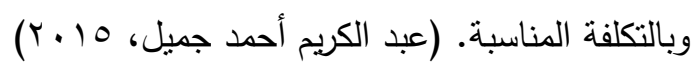
مفهوم الكفاءة: يستخدم مفهوم الكفاءة في مجالات عديدة، وهو مفهوم نسبي لدي لاعي الاقتصاديين، حيث تختلف الكفاءة باختلاف مستوي الوحدة الاقتصادية (سواء كانت مزرعة أو

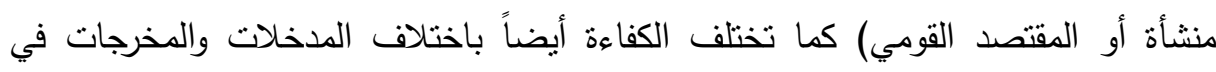
العملية الإنتاجية الكفاءة تعبر عن مدى كفاءة إستخدام العناصر الإنتاجية وتطبق فى علاقات

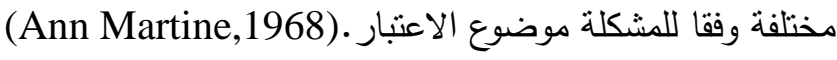
مفهوم دالة الإنتاج: هى العلاقة العينية بين عناصر الإنتاج الداخلة فى العملية الإنتاجية وبين كمية الإنتاج من سلعة معينة فى فترة زمنية محددة. (محسن حسن العمورى، ع ( ب ب). الكفاءة والفعالية: الكفاءة هي مقياس جزئي من مقاييس الفعالية، فالفعالية تعبر عن درجة

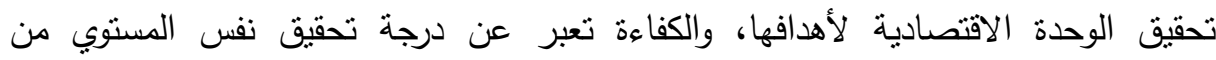

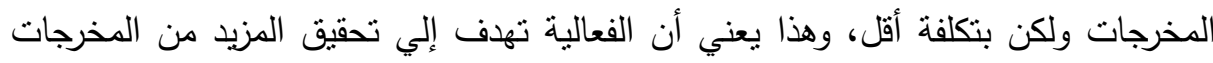

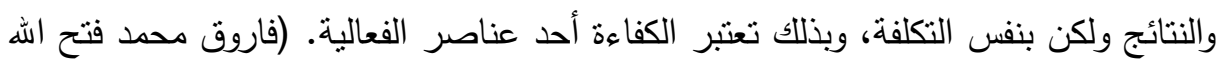
مفهوم دالة التكاليف الزراعيه: هى العلاقة بين التكاليف الزراعية الكلية ومستوى الإنتاج. وتنين تلك الدالة التكاليف المنعلقة بكل مستوى إنتاجى فى ظل اثمان معينة لعوامل الأنتاج وعلى أساس إفتراض أن الأسلوب الإتتاجى ذات التكاليف الأدنى كان قد اختير دائمأ من بين

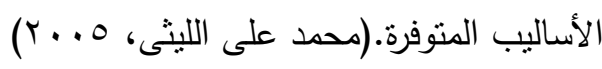
الموارد الاقتصادية: يختلف مفهوم المصدر عن المورد فالأول وهو المصدر يقصد به موضوع

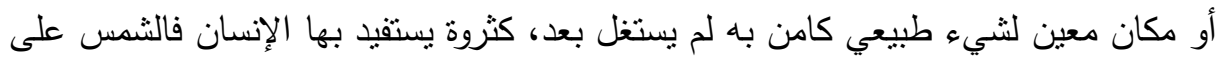

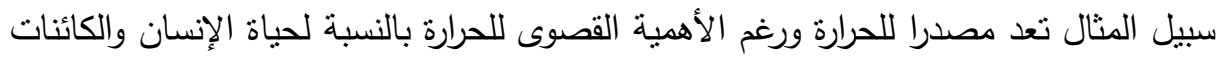
الأخرى إلا إننا لا نعتبر الحرارة ثروة مستغلة بيد الإنسان وحينما يستغلها فإنها أي الحرارة

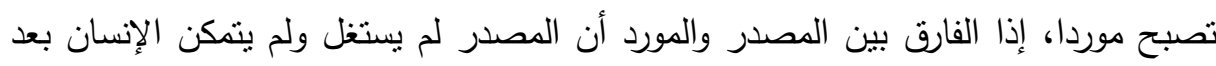

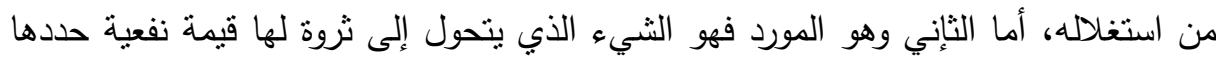

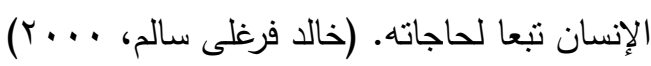




\section{إجباءاهي التراسما}

منهج البحث: من أجل تحقيق أهداف البحث قام الباحثون بإستخدام المنهج الوصفي التحليلي لتكوين الإطار النظري للبحث في جمع البيانات بإستخدام مصدرين أساسين

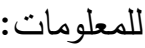
المصادر الثانوية: والتي تتمثل في الكتب والمراجع العربية والأجنبية ذات التأثير والدوريات

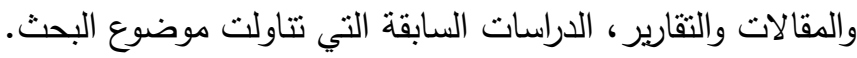
المصادر الأولية: والتي تتمنل في تجميع البيانات الأولية من خلال إستمارة استقصاء كأداة

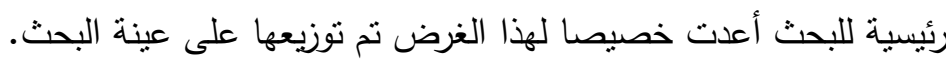

\section{And}

تتمثل حدود البحث في الآتي:

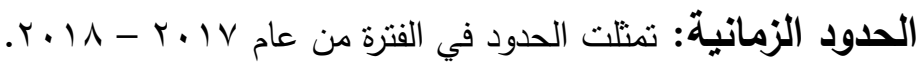
الحدود المكانية: تمثلت الحدود المكانية فى محافظة الوادى الجديد.

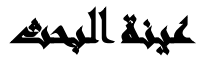

إقتصر البحث على سحب عينة ممثلة في كسر معاينة من مزراعى محصول القمح

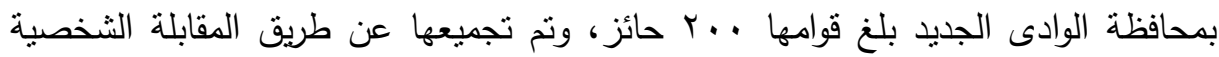

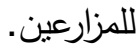

\section{إلجراعاهت الهيث}

أداة الدراسة: تم تصميم استمارة استبيان خاصة باستطلاع آراء المزارعين تضمنت أبعاد الدراسة حول أهم العوامل الإنتاجية التي تؤثر علي إنتاج الفدان من محصول القمح.

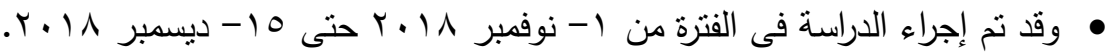


• وقد تم استخدام بعض أساليب النحليل الإحصائى الوصفى والكمى، متل بعض المعايير

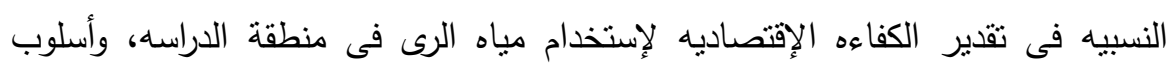

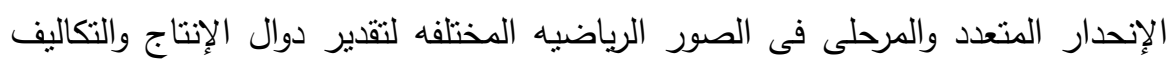

لأهم المحاصيل المنزرعه بمنطقة الدراسة.

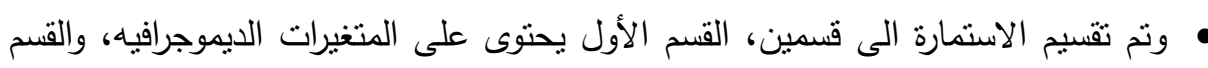

$$
\text { الثانى يحتوى على أبعاد الدراسة. }
$$

القسم الأول: هذا القسم يتضمن المتغيرات الديموجرافيه وتم سؤال العينة عن كل من (المؤهل

$$
\text { الدراسي، والنوع، عدد الاولاد، المستوى الوظيفي). }
$$

القسم الثانى: من استمارة الاستقصاء: هذا القادي، القسم فى الستمارة الاستقصاء يحتوى على أبعاد

\begin{tabular}{|c|c|}
\hline 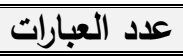 & أبعاد الاستبيان \\
\hline آ أسئلة & طريقة الرى المستخدمة والمعدات المستخدمة \\
\hline ع ع أسئلة & حجم الملكية ونوعها \\
\hline م آسئلة & العنصر البشرى الكستخدم وتكلفنته \\
\hline ع ع أسئلة & كمية العمل الآلى وتكلفنها \\
\hline آ أسئلة & تكاليف الإنتاج \\
\hline ي أسئلة & كمية مستلزمات الإنتاج \\
\hline آ أسئلة & كمية الناتج الرئبسى وألثانوى \\
\hline V V V أسئلة & قيمة الايراد \\
\hline 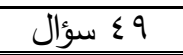 & إجمالّي الاستنيان \\
\hline
\end{tabular}

الدراسة، الجدول التالى يعرض أبعاد الدادئاد الدراسة.

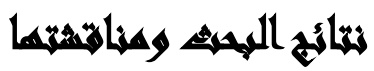

التقدير الإحصائي لدوال إنتاج محصول القمح: تم تقدير معالم الدالة الإنتاجية

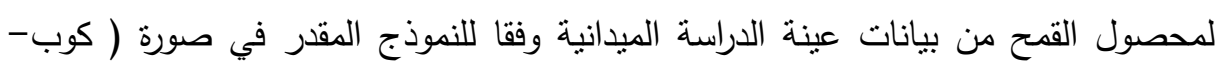

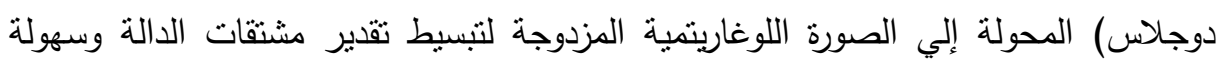

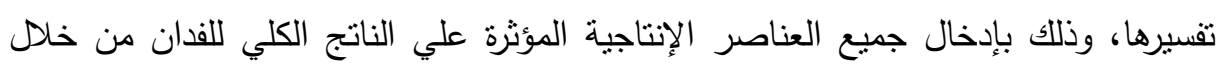

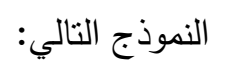
لو ص= أ + بالى لو س + + بr لوس س + بك لو سك + بع لو سع + به لو سه. 


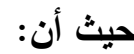
ص: الناتج الكلي للفدان من القمح (طن). س ا : كمية العمل البشري (رجل/ فدان). س ب ك: كمية العمل الآلي (ساعة). سبז: كمية النقاوى (كجم/ فدان). س ع : كمية السماد الفوسفاتي بالوحدة الفعالة. س 0: كمية السماد الآزوتي بالوحدة الفعالة.

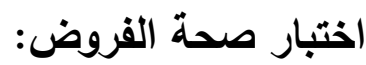

اختبار صحة الفرض الأول: ينص الفرض الأول علي: وجود تأثير للمتغيرات المستقلة (العمل

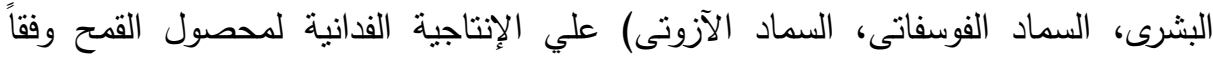

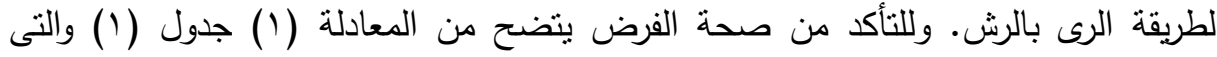

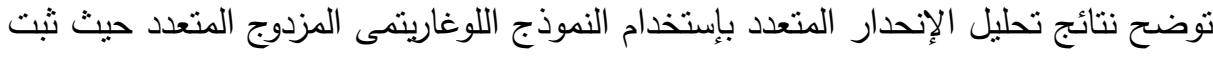

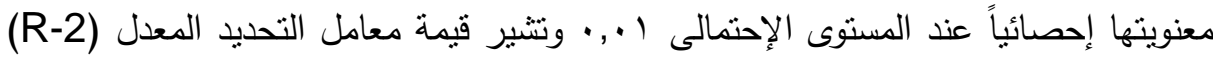

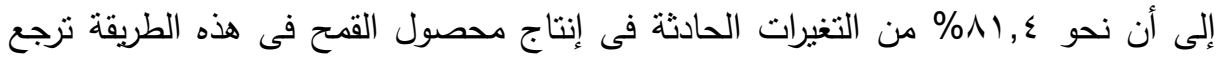

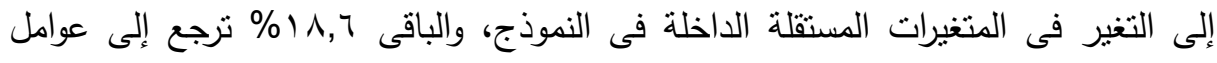

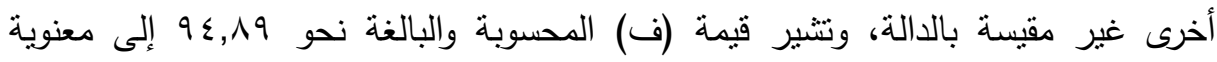
النموذج إحصائياً، وصلاحيته وملائيته لطبيعة البيانات الإحصائية للظاهرة محل الثئة الدراسة،

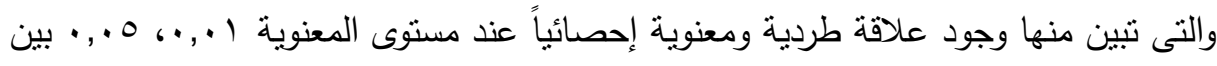

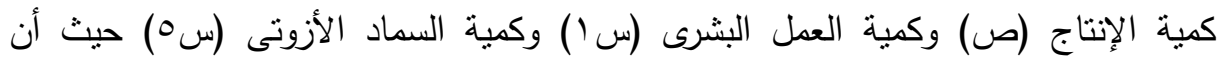
إثناراتهما تتفق والمنطق الإقتصادى، فى حين لم تثبت معنوية باقى المنتيرات مع أنهم بتقفوا

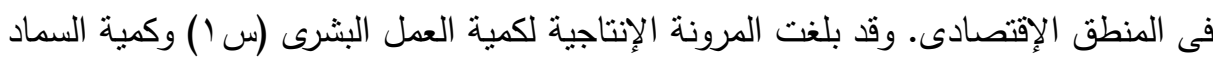

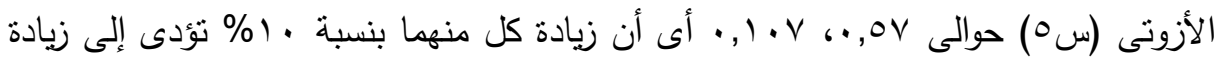

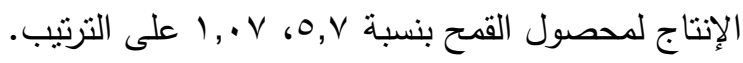


كما تبين من المعادلة (r) بنفس الجدول والتى تمثل دالة الإنتاج الفيزيقية لهذه الطريقة

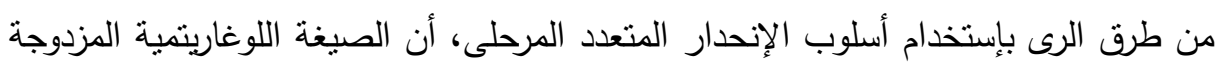

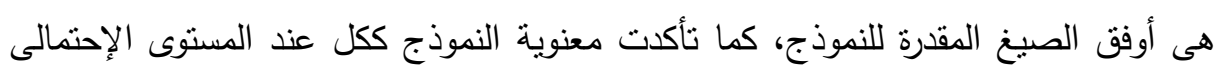

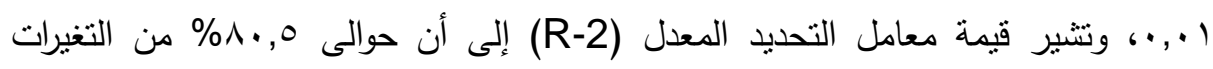

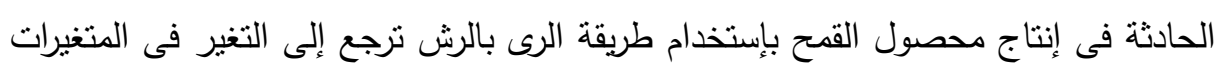

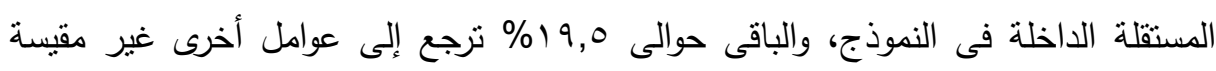

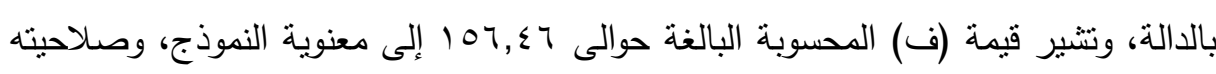
وملائمنه لطبيعة البيانات الإحصائية للظاهرة محل الدراسة.

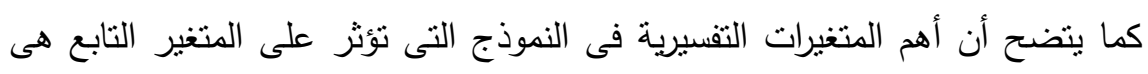

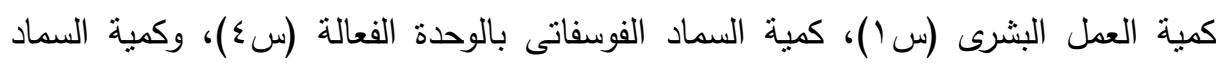

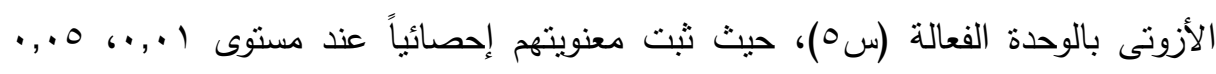

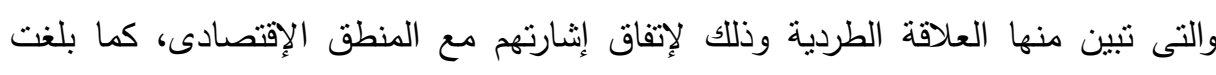

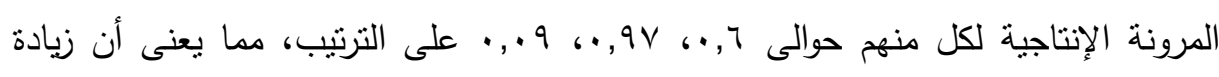

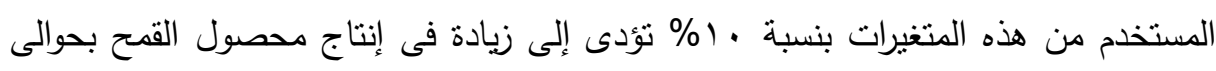

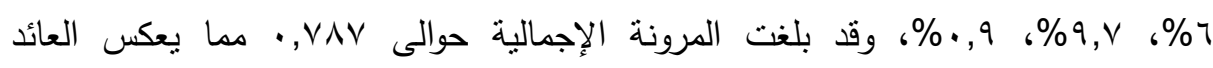

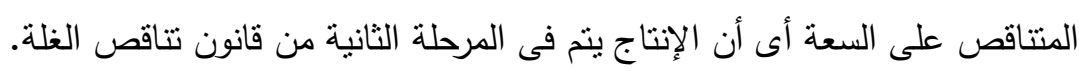

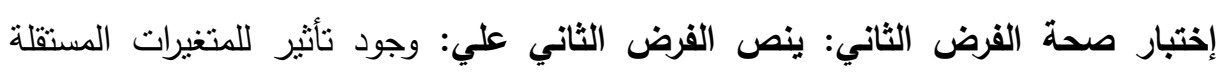

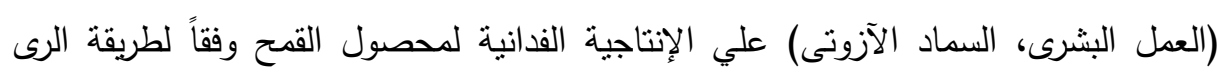

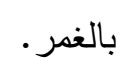
يتضح من المعادلة (1) جدول (Y) والتى توضح نتائج تحليل الإنحدار المتعدد بإستخدام النموذج اللوغاريتمى المزدوج المتعدد حيث ثبت معنويتها إحصائياً عند المستوى الإحتمالى لئى

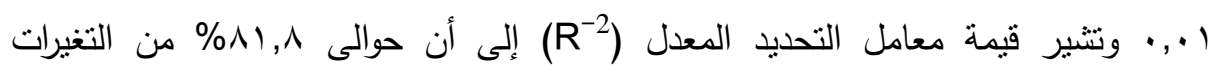
الحادثة فى إنتاج محصول القمح فى هذه الطريقة نرجع إلى التغير فى المتغيرات المستقلة

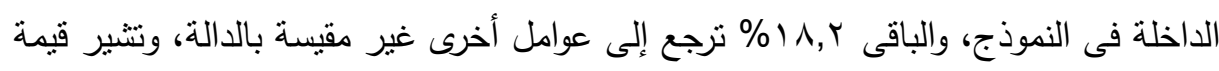

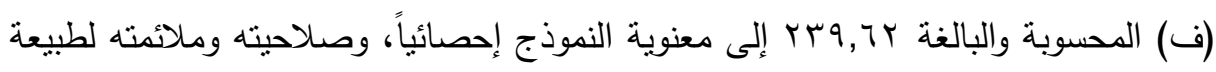

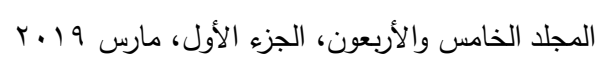


البيانات الإحصائية للظاهرة محل الدراسة، والتىى تبين هنها وجود علاقة طردية ومعنوية إحصائياً عند مستوى المعنوية ا.,., بين كمية الإنتاج (ص) وكمية السماد الأزوتى (سه)

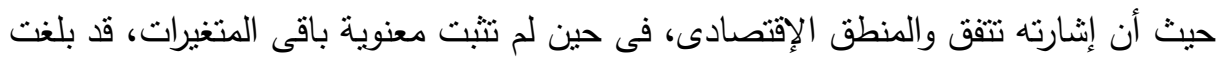

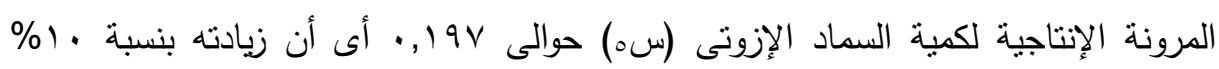

$$
\text { تؤدى إلى زيادة الإنتاج لمحصول القمح بنسبة لو 1, 1. }
$$

كما تبين من المعادلة (r) بنفس الجدول والتى تمثل دالة الإنتاج الفيزيقية لهذه الطريقة

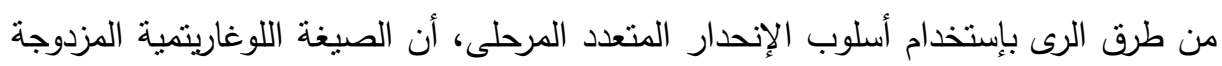

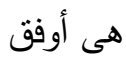

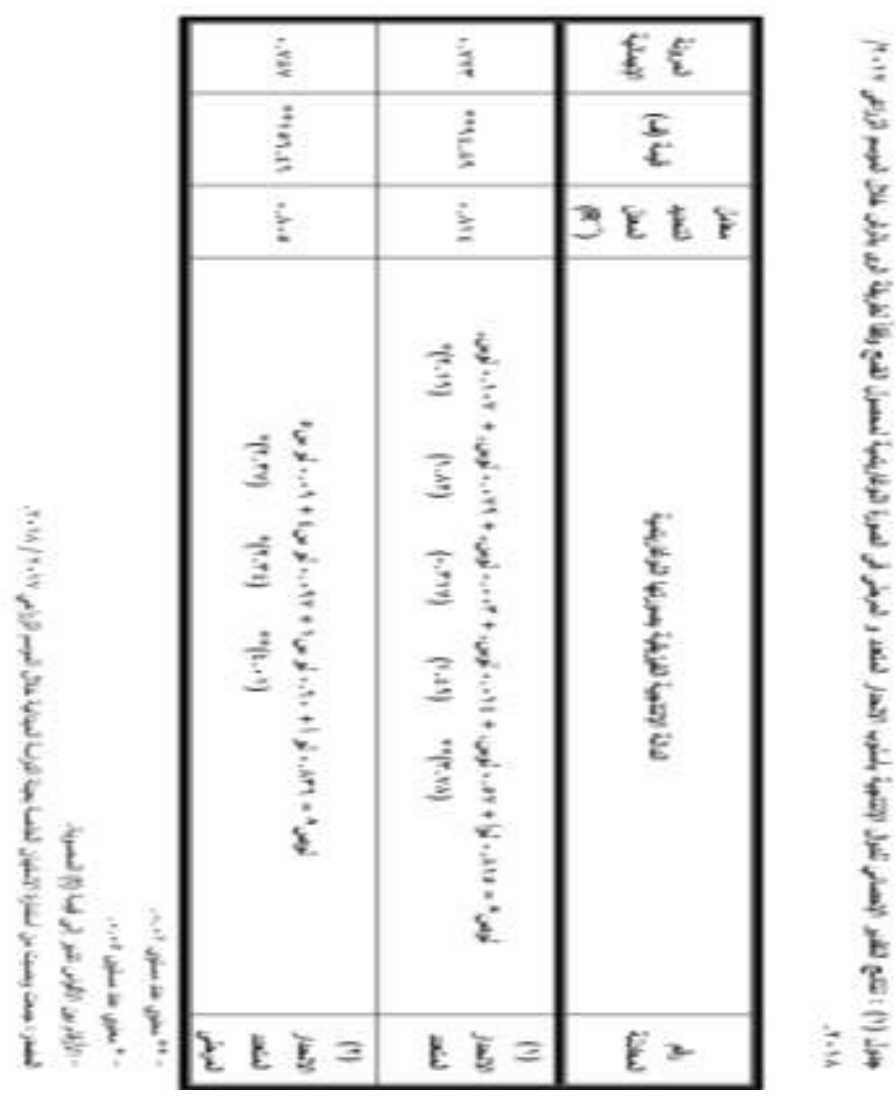

المجلد الخامس والأربعون، الجزء الأول، مارس 9 . 
الصيغ المقدرة للنموذج، كما تأكدت معنوية النموذج ككل عند المستوى الإحتمالى

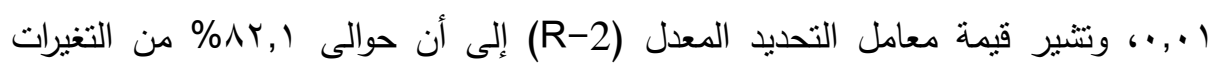
الحادثة فى إنتاج محصول القمح بإستخدام طريقة الرى بالغمر ترجع إلى التغير فى المتغيرات

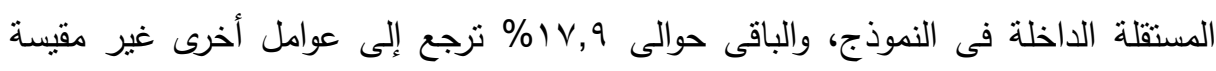

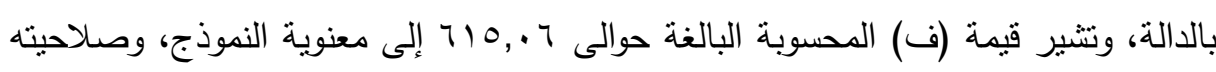
وملائمته لطبيعة البيانات الإحصائية للظاهرة محل الدانة الدراسة.

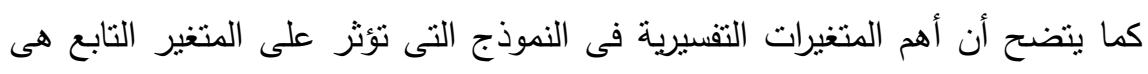

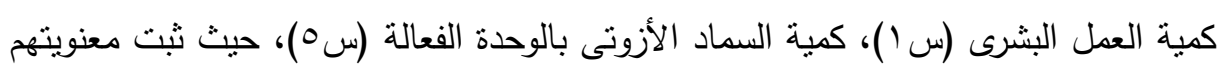

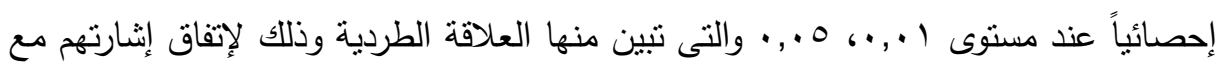

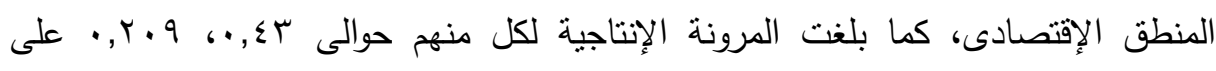

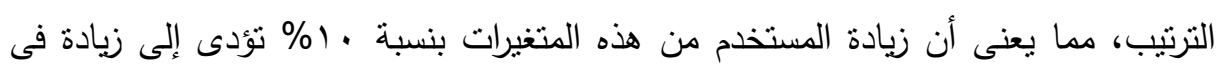

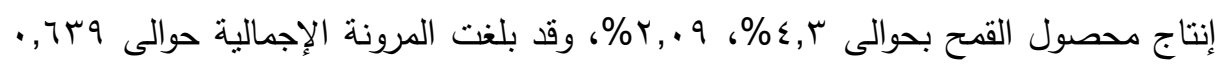

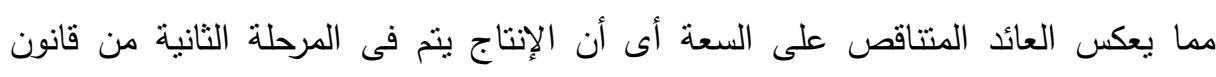
تناقص الغلة. التقدير الإحصائي لاوال التكاليف الإنتاجية لمحصول القمح: أمكن تقدير دالة التكاليف الإنتاجية لمحصول القمح بعينة الدراسة الميدانية بمحافظة الوادى الجديد وذلك الإسية

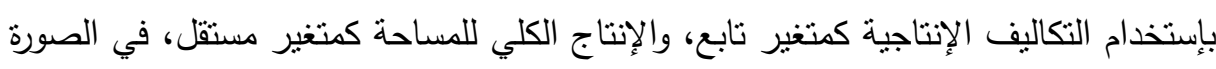

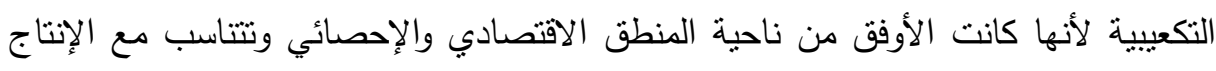

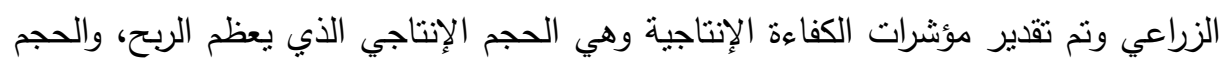

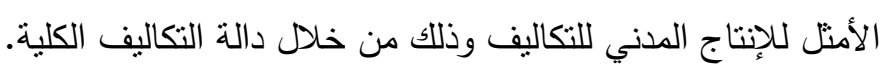
1 - وفقاً لطريقة الرى بالرش: بدراسة العلاقة بين التكاليف الكلية والإتتاج لزراع عينة الدراسة دلهان

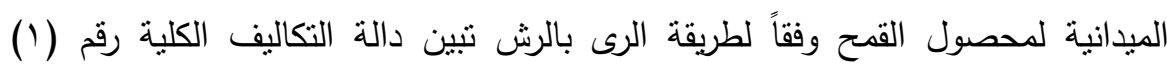

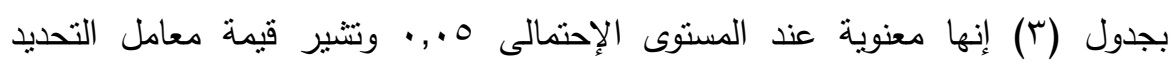

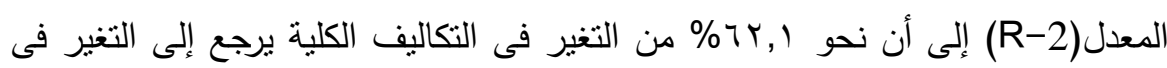
كمية الإنتاج. 
ومن خلال إثتقاق دالة التكاليف الحدية المقدرة بالمعادلة رقم (Y) بذات الجدول السابق

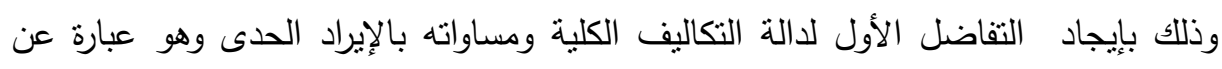
منوسط سعر .

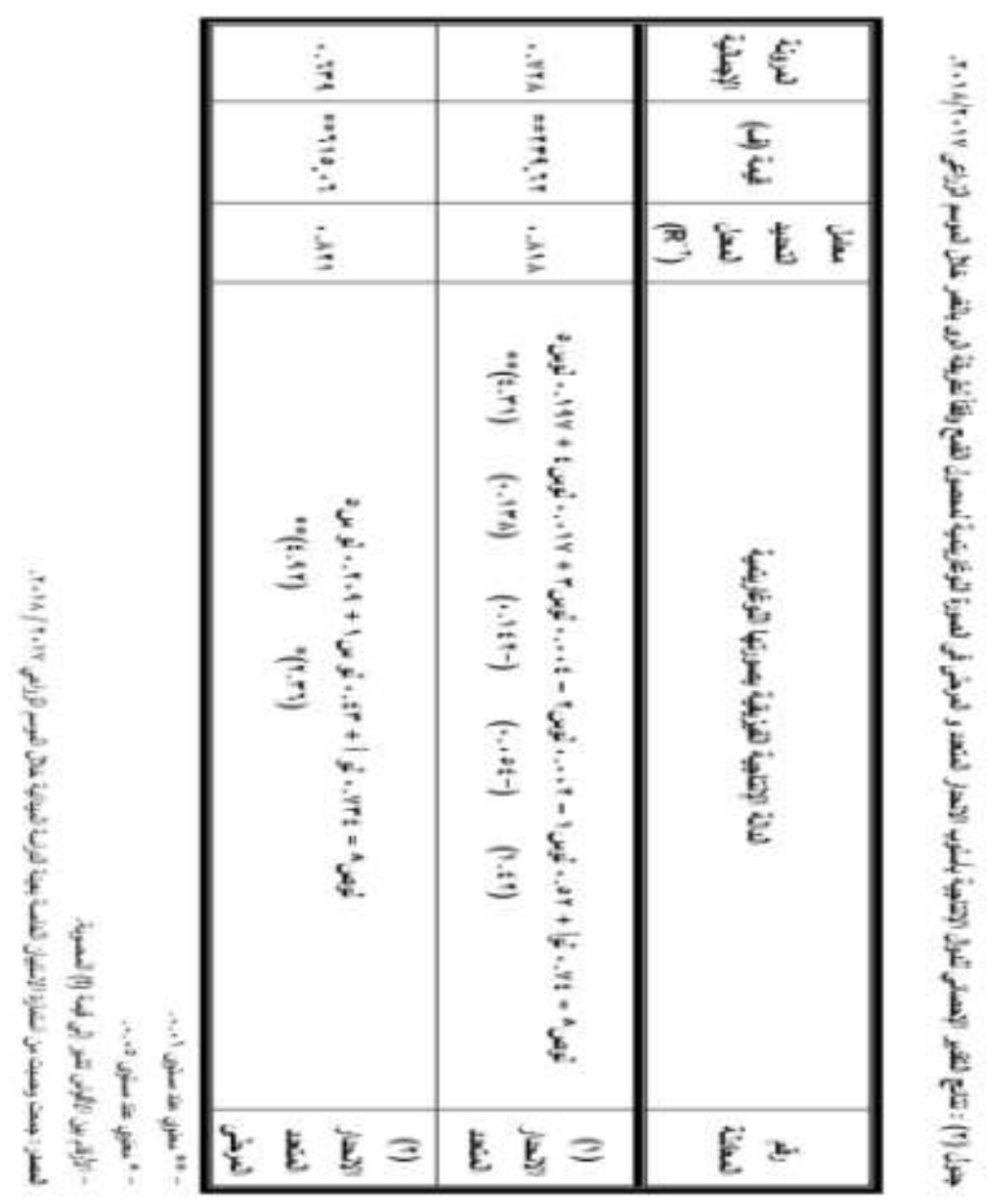


بيع أردب القمح والذى يبلغ نحو 19,00 إ جنيه، تبين أن كمية الإتتاج المعظمة للربح

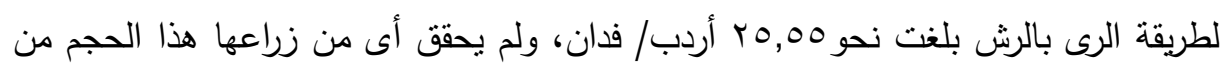
الإنتاج.

بينما أثنارت التقديرات أن حجم الإنتاج الأمتل الذى يدنى التكاليف إلى أدنى نقطة والذى

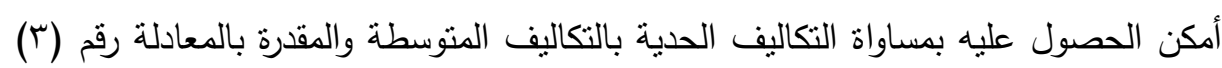

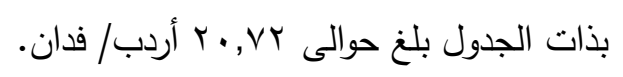
r - وفقاً لطريقة الرى بالغمر : بدراسة العلاقة بين التكاليف الكلية والإنتاج لزراع عبان علينة الدراسة

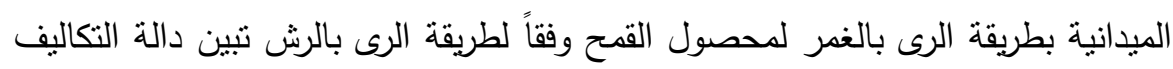

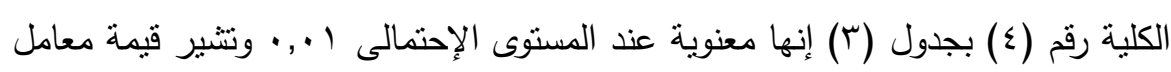

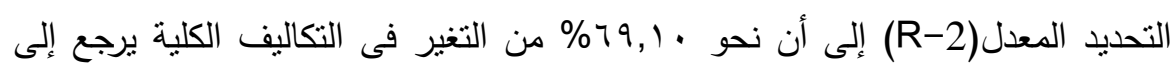
التغير فى كمية الإنتاج. ومن خلال اشتقاق دالة التكاليف الحدية المقدرة بالمعادلة رقم (0) بذات الجدول السابق

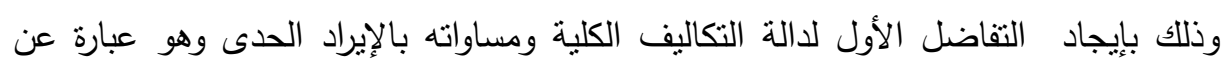
متوسط سعر بيع أردب القمح والذى يبلغ نحو هـ,9,1 جنيه، وتبين أن كمية الإنتاج

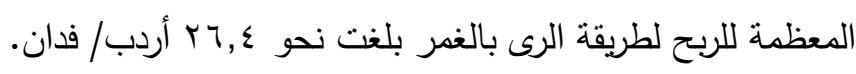

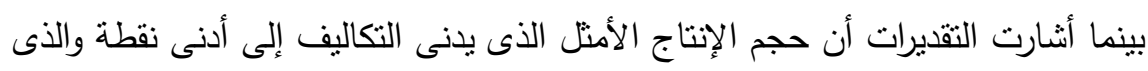

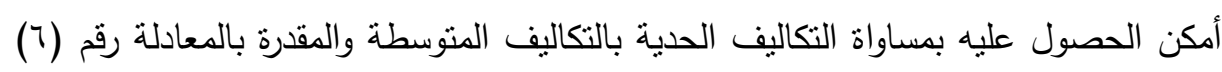

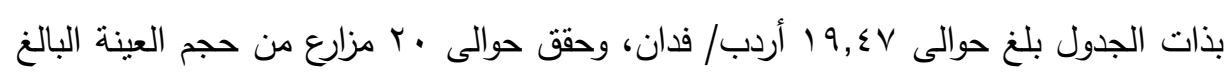

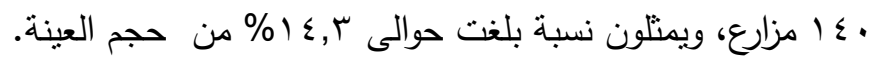

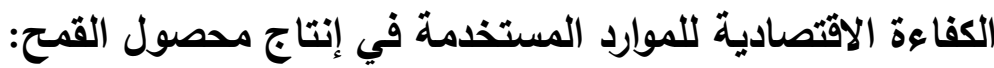

1- وفقاً لطريقة الرى بالرش: يتضح من البيانات الواردة بجدول (ع) أن الإنتاجية

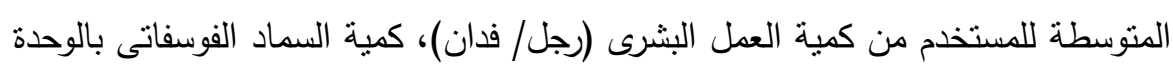

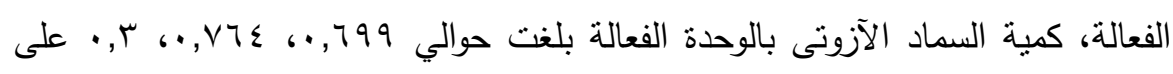

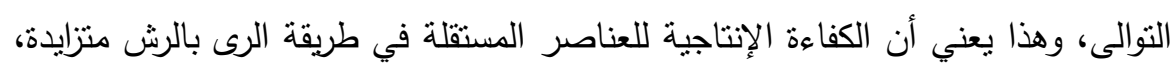
بينما بلخ الناتج الحدي من دالة إنتاج محصول القمح لطريقة الرى لئه 
مجلة العلوم البيئية

معهد الدراسات والبحوث البيئية - جامعة عين شمس لهن لهن

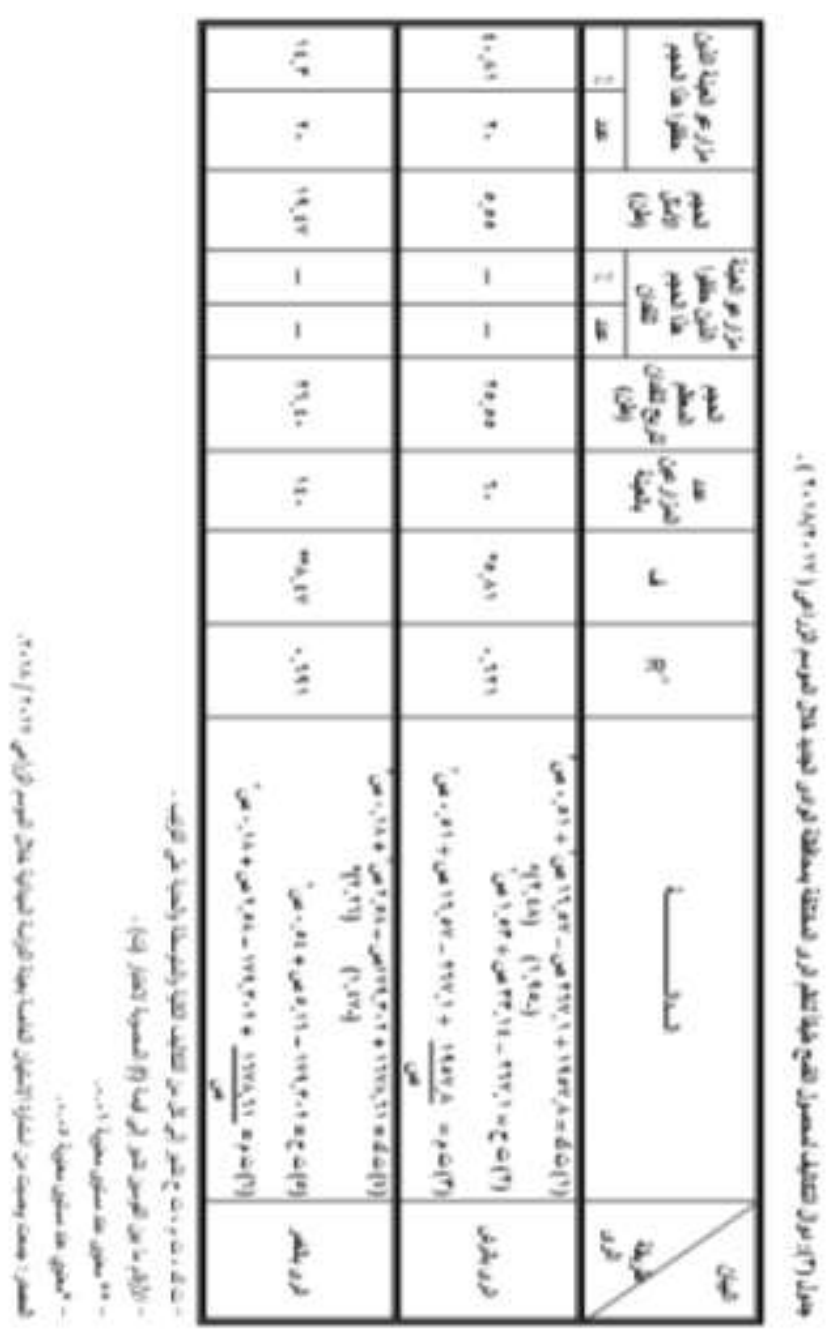

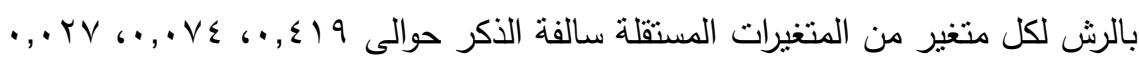
على التزتيب وهذا يعني أن الزيادة الحاصلة فى كمية عنصر الإنتاج تكون بنسبة أقل من فئن

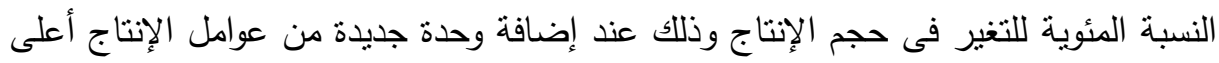

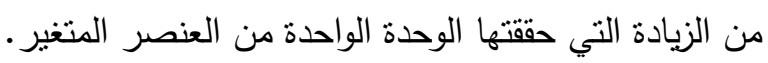

$$
\text { المجلد الخامس والأربعون، الجزء الأول، مارس } 19
$$


قدرت قيمة معامل الكفاءة الاقتصادية لتتغير كمية العمل البشرى (رجل/ فدان) بنحو

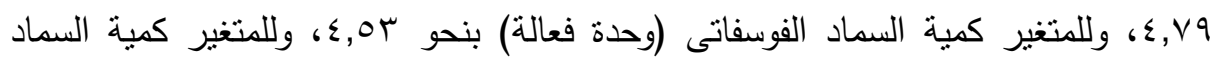

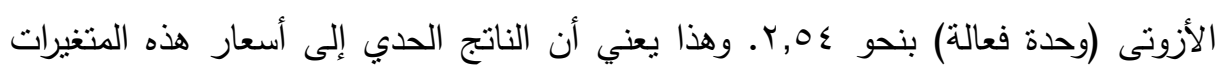

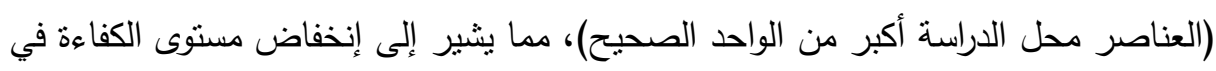

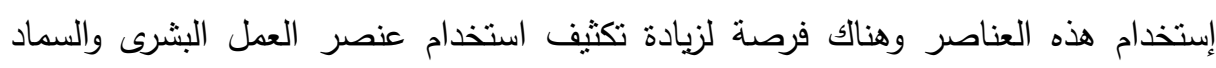

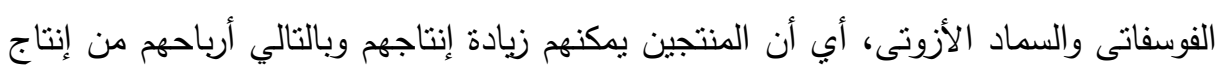

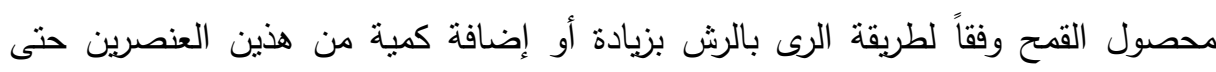

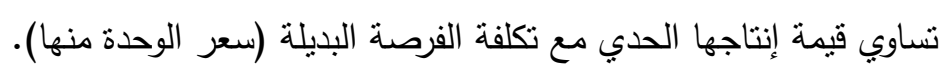

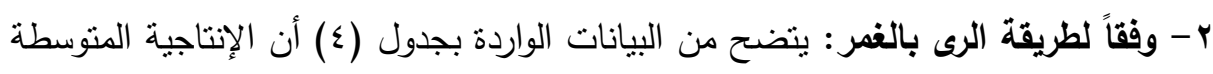

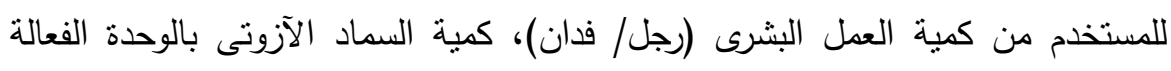

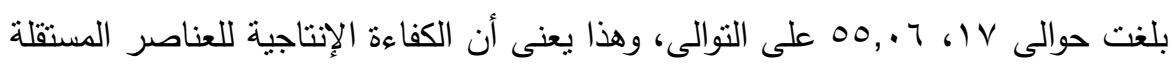
في طريقة الرى بالغمر متزايدة.

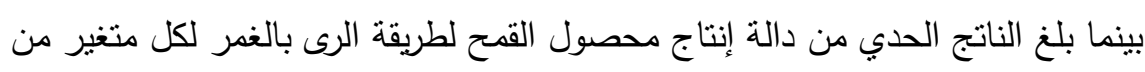

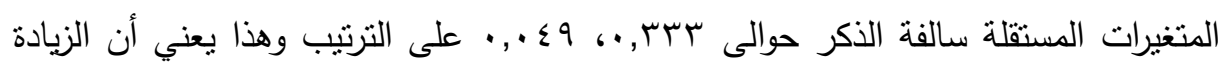

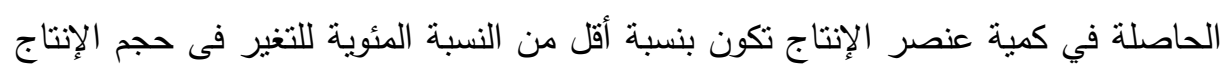

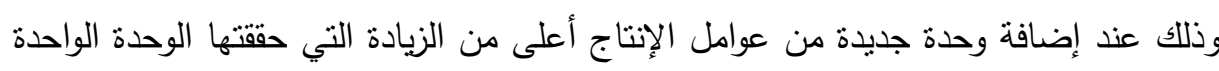

$$
\text { من العنصر المتغير. }
$$

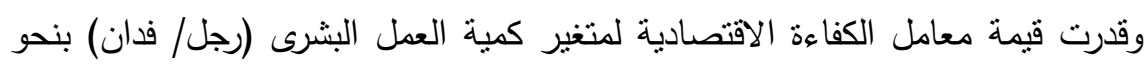

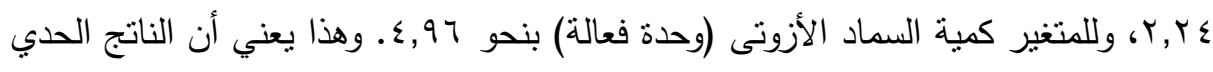

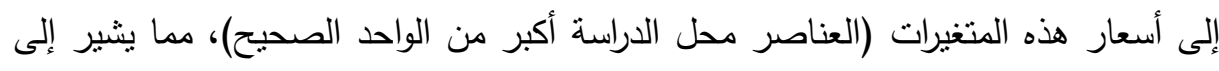

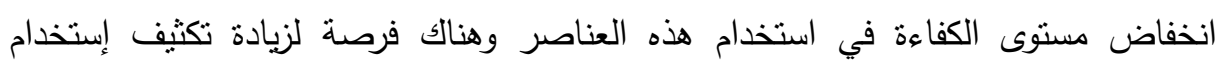

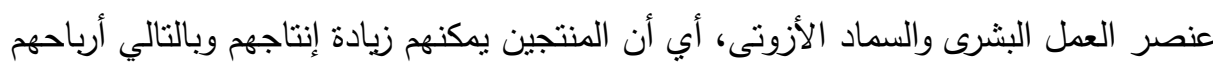

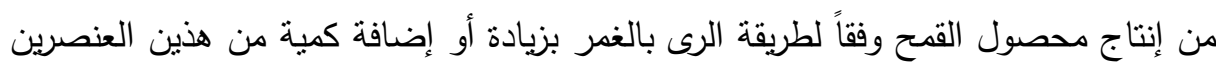
حتى تساوي قيمة إنتاجها الحدي مع تكلفة الفرصة البديلة (سعر الوحدة منها). 
جدول(؛): الكفاءة الاقتصادية للموارد المستخدمة على مستوى طرق الرى المستخدمة فى عينة الدراسة

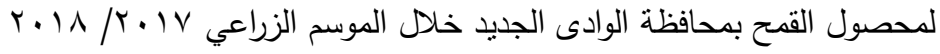

\begin{tabular}{|c|c|c|c|c|c|}
\hline \multicolumn{2}{|c|}{ الرى بالغمر } & \multicolumn{3}{|c|}{ الرى بالرش } & \multirow[b]{2}{*}{ الرى / المتغير / / / / / / } \\
\hline والأزمبادة & كمية العمل & والأزوتيةت & 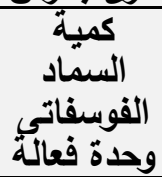 & 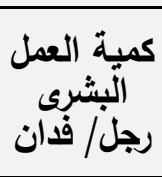 & \\
\hline$\overline{C, Y \cdot q}$ & $\cdot, \varepsilon \Gamma$ & $7 \cdot, \cdot 9$ & $\cdot, \cdot, 9 V$ & $\cdot, 7$. & المرونة \\
\hline . & $\cdot, \vee \vee \vee \top$ & $\cdot, r$ & $\cdot, \vee \backslash \leq$ & $\cdot, 799$ & الناتج المتوسط \\
\hline$\cdot, \cdot \leq 9$ & . & $\cdot, \cdot Y V$ & $\cdot, \cdot \vee \varepsilon$ & $\cdot, \varepsilon 19$ & الناتج الحدي \\
\hline$\varepsilon 19, \Gamma_{0}$ & $\xi 19, \Gamma_{0}$ & $\$ 19,00$ & $\sum 19,00$ & $\sum 19,00$ & سعر الإردب \\
\hline$r \cdot, 0 \leqslant$ & $1 \Gamma q, 7 \varepsilon$ & $11, r r$ & $\Gamma, \cdot \leq$ & $1 \vee 0,19$ & قيمة الناتج الحدي \\
\hline$\varepsilon, 1 \leqslant$ & $7 r, .9$ & $\varepsilon, \varepsilon \varepsilon$ & $7, \wedge 0$ & 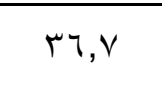 & سعر الوحدة من \\
\hline$\{, 97$ & $T, Y \Sigma$ & $Y, O \varepsilon$ & $\varepsilon, O T$ & $\varepsilon, \vee q$ & معامل الكفاءة \\
\hline
\end{tabular}

- الناتج الحدي للعنصر = مرونة العنصر (من الدالة اللوغاريتمية) × الناتج المنوسط للعنصر

- الناتج المتوسط = الناتج الكلي/ عدد الوحدات المستخدمة من المورد الإنتاجي المتغير . - قيمة الناتج الحدي = الناتج الحدي × سعر الوحدة من الناتج.

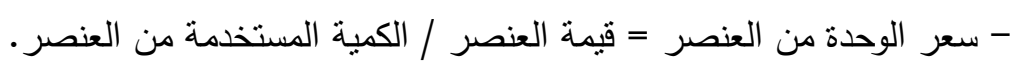

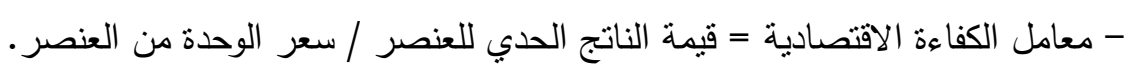

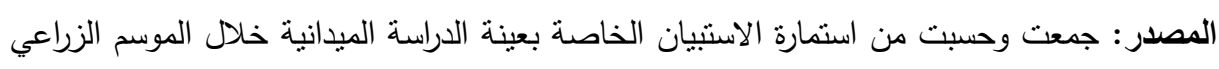
$r+11 / r+1 \mathrm{~V}$ مؤثرات كفاءة إستخدام مياه الرى لإنتاج محصول القمح وفقاً لطريقة الرى بعينة الدراسة: بدراسة بيانات جدول (0) لقياس مؤشرات إستخدام مياه الرى لإنتاج محصول

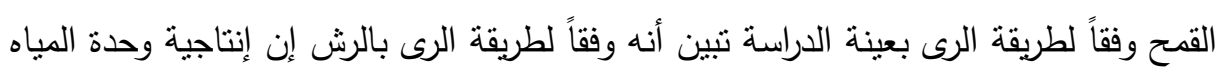

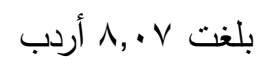


جدول(•): مؤشرات كفاءة استخدام مياه الرى لإنتاج محصول القمح وفقاً لطريقة الرى.

\begin{tabular}{|c|c|c|c|c|c|}
\hline الري للتكاليف تكاليف & كمية المياه والألفدة النازتج & تكلقة رئ وحدة الإنتاج & من وحدة الإيراد & إنتاجية & طريقة \\
\hline$r 1,99$ & •, IY & ro1, $\cdot \Lambda$ & $Y \backslash V Y, \Lambda \Lambda$ & $\Lambda, \cdot V$ & رش \\
\hline$r q, 0 \leqslant$ & $\bar{e}, \mathrm{YV}$ & $r \wedge q, \ldots$ & $\Delta \vee \neg, 1 T$ & r,vo & غمر \\
\hline
\end{tabular}

- إنتاجية وحدة المياه بالطن = كمية الناتج الفيزيقى بالطن ؛ كمبة المياه اللازمة لنضج المحصول

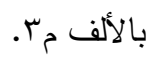

- صافى الإيراد من وحدة المياه بالجنيه = صافى الإيراد الفدانى بالجنيه ؛ كمية المياه اللازمة لنضج

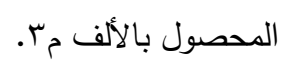

- تكلفة رى وحدة الإنتاج بالجنيه / طن = تكاليف رى الفدان بالجنيه ؛ كمية الإنتاج الفيزيقى للفدان.

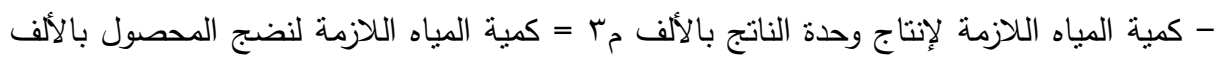

$$
\text { مr - كمية الإنتاج الفيزيقى للفدان بالطن. }
$$

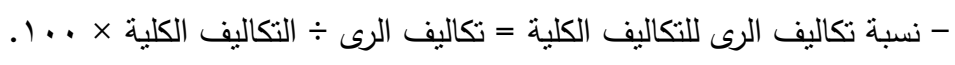

المصدر : جمعت وحسبت من إستمارة الاستنيان.

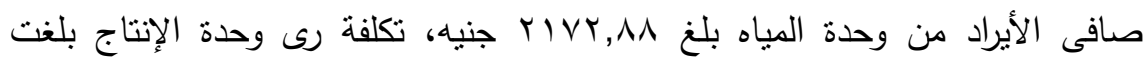

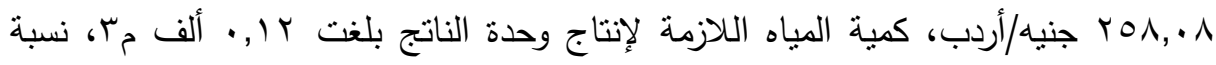

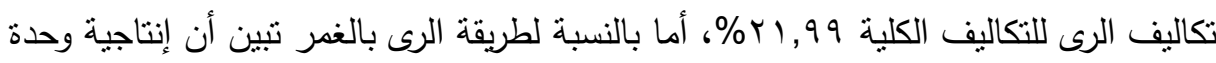

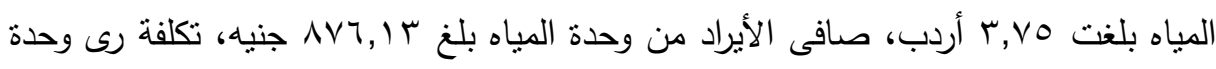

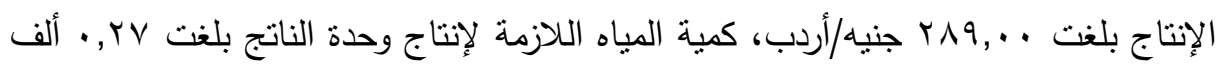

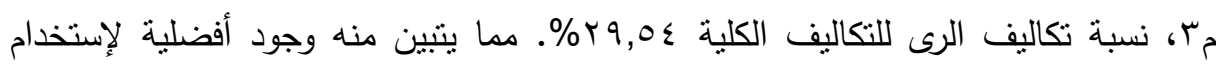
طريقة الرى بالرش مقارنة بإستخدام طريقة الرى بالغمر. 


\section{النئوسياتص}

$$
\text { • التوسع في إستخدام نظم الري المنطورة. }
$$

• استخدام الزراعة العضوية والحيوية للحد من الأسددة والمبيدات الكيماوية الملوثة للبيئة.

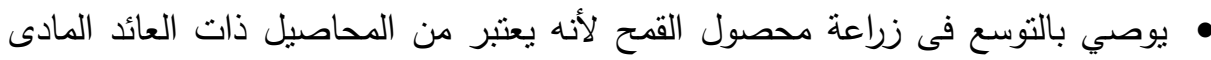
المرتفع. • ضرورة العمل على زيادة البحث عن موارد المياه الجوفية ووضع ضوابط للآبار التي تم حفرها وحسن إدارتها. • ت توفير وسائل نقل وأماكن تخزين مناسبة للحد من تلف محصول القمح. • مساعدة الدولة مزارعي الوادى الجديد من خلال حفر الأبار العميقة التي يمكن أن توفر لهرئر المياه اللازمة للزراعة.

\section{المرالئ2}

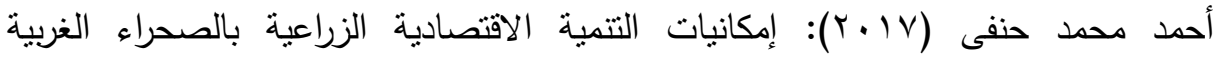

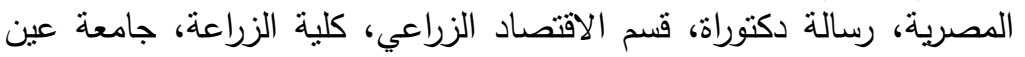

$$
\text { شمس. }
$$

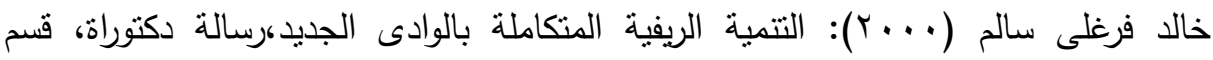

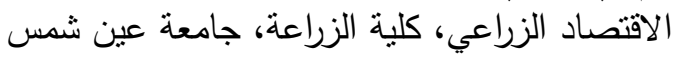

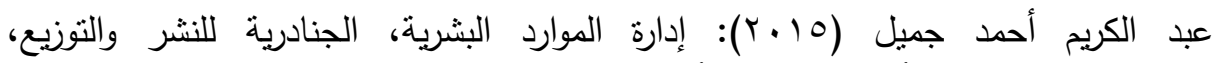

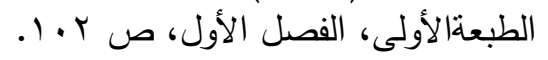

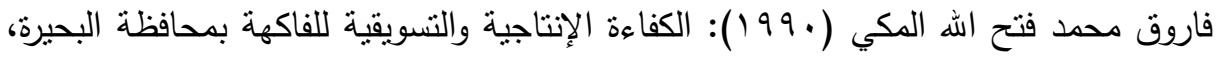

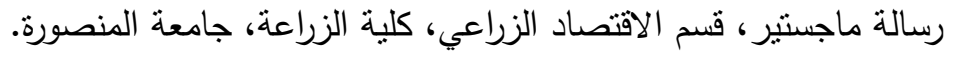

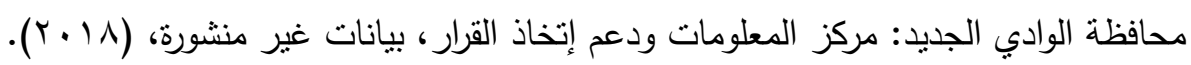

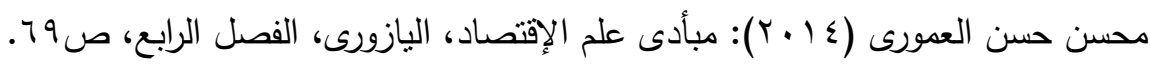
محمد على الليثى (0. . ب): النظرية الإقتصادية الجزئية، مؤسسة شباب جامعة الأسكندرية، 


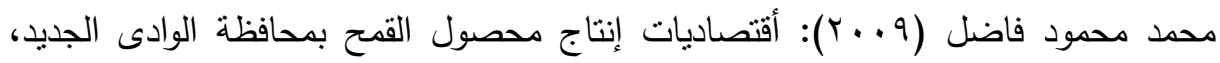
رسالة ماجستير، قسم الاقتصاد الزراعى، كلية الزراعة، جامعة المنيا.

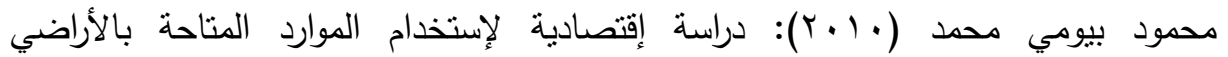

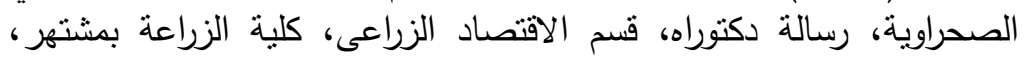
جامعة بنها.

منى صالح إمام: دراسة اقتصادية تحليلية لمحصول القمح فى الوادى الجديد، المجلة المصرية

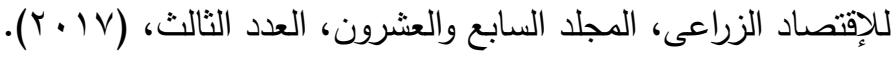

نادية محمود مهدى، إلهام إبراهيم يونس: تقييم القدرة الإنتاجية للإراضى الزراعية بمحافظات

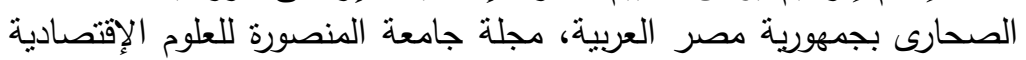

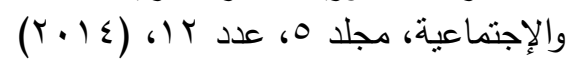

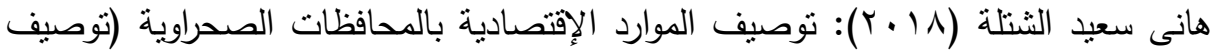

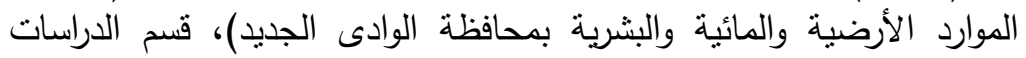

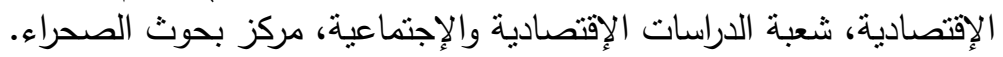

Ann Martine,(1968): Economics \& Agriculture", Rouledgan Kegan Poul, London. 
مجلة العلوم البيئية

معهد الدراسات والبحوث البيئية - جامعة عين شمس لبه

\title{
PRODUCTION AND ECONOMIC EFFICIENCY OF WHEAT CROP UNDER LRRIGATION SYSTEMS IN NEW VALLEY GOVERNORATE
}

\author{
Mohamed, S. Alsayed ${ }^{(1)}$; Mohamed, E. El-Nennah ${ }^{(2)}$; \\ Hany, S. Abd El-Rahman ${ }^{(1)}$ and Mohamed, A. Al- Sentrisy ${ }^{(2)}$ \\ 1) Desert Research Center 2) Faculty of Agriculture, Ain Shams \\ University
}

\begin{abstract}
The wheat crop is considered as one of the most important food crops on which the living organisms depend as a basic element of food. Moreover, many services and industries contribute in its preparation that allows multiple fields of investment and operation. Some of it is used in bread manufacturing, it can be used as a direct food for animals, and it also enters into feed industry as well as making different baked goods. the research aimed at estimating the production functions and the costs of the wheat crop, Estimating some measures of productive and economic efficiency of the crop and estimating the size that maximizes the profit as well as the optimal size that reduces the costs and comparing them with the size produced by the farmers in different farm capacities. The research hypotheses included a moral effect of the independent variables (human work, nitrogen fertilizer, phosphate fertilizer) on the productivity of the wheat yield according to the method of spray irrigation. The effect of the independent variables (human work, nitrogen fertilizer) on the productivity of the wheat yield according to the method of flooded irrigation was also included. The descriptive analytical method was used to form the theoretical framework for the research. The primary data were collected through a survey form as a main research tool prepared specifically for this purpose, which was distributed to a sample of 200. The results showed that the most important explanatory variables according to the spray
\end{abstract}

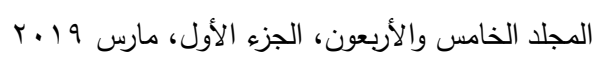


method affecting the dependent variable were the quantity of human work (S1), and the quantity of the phosphate fertilizer in the effective unit (S4) and the quantity of the nitrogen fertilizer in the effective unit (S5), where they were statistically moral at $0.01,0.05$, which showed the positive relationship due to the agreement of their reference with economic logic.

It was also found that the most important explanatory variables according to the method of flooding irrigation that affect the dependent variable were the quantity of human work (S1), and the quantity of nitrogen fertilizer in the effective unit (S5), where they were statistically moral at level $0.01,0.05$, which showed the positive relation and this is due to the agreement of its reference with the economic logic. The irrigation water production index was calculated according to the irrigation method. The water unit productivity was 8.07 Ardab. The net revenue from the water unit reached 2,172.88 pounds. The unit cost of production amounted to 258.08 pound /Ardab. The quantity of water needed to produce the unit The total irrigation cost was 0.12 thousand $\mathrm{m} 3$, the irrigation cost ratio for the total cost was $21.99 \%$. As for the irrigation method, the water unit productivity was 3.75 ardeb, the net revenue from the water unit was 876.13 pounds, the production unit cost was 289.00 pounds /Ardab, To produce the output unit of 0.27 thousand $\mathrm{m} 3$, the proportion of irrigation costs per ton The total rate is $29.54 \%$. Which shows that there is a preference for the use of spray irrigation method compared to the method of irrigation by flooding.

The study recommended the expansion of the use of advanced irrigation methods and appropriate irrigation methods, the use of organic and biological agriculture to reduce fertilizers and chemical pesticides contaminated with the environment, and the expansion of the cultivation of wheat because it is a crop with a high return of the material, the need to work to increase the search for Groundwater resources and the establishment of controls for wells that have been dug and work on the efficiency of use. 